\title{
ARTÍCULO
}

\section{Identidad, sometimiento y exclusión. Vicisitudes de la tolerancia en} el mundo antiguo ${ }^{1}$

\section{Identity, submission and exclusion. Vicissitudes of tolerance in the ancient world}

\author{
Manuel Escamilla Castillo \\ Departamento de Filosofía del Derecho \\ Universidad de Granada
}

Fecha de recepción 29/12/2019 | De aceptación: 14/04/2020 | De publicación: 15/06/2020

\section{RESUMEN}

La tolerancia es un rasgo definitorio de la sociedad moderna que surge como reacción a una situación anterior contraria a ella y que, a su vez, definió a las sociedades humanas desde el principio de los tiempos. Esta situación anterior y contraria a la tolerancia es la de sociedades definidas por identidades colectivas. Estudiar el colectivismo identitario es una buena manera de conocer la idea, exigencias y límites de la tolerancia en nuestras sociedades. Este trabajo pretende hacerlo analizándolo en las primeras sociedades históricas del ámbito europeo.

\section{PALABRAS CLAVE}

Tolerancia, Identidad, Grupo, Religión, Judaísmo, Roma antigua, Cristianismo.

\section{ABSTRACT}

Tolerance is a defining feature of modern society. It arose as a reaction to a previous situation contrary to it and which, in turn, defined human societies from the beginning of time. This previous situation and contrary to tolerance is that of societies defined by collective identities. Studying identity collectivism is a good way to know the idea, demands and limits of tolerance in our societies. This work intends to do it by analyzing it in the first historical societies of the European sphere.

\section{KEY WORDS}

Tolerance, Identity, Group, Religion, Judaism, Ancient Rome, Christianity.

\footnotetext{
${ }^{1}$ Proyecto de Investigación RTI2018-093498-B-I00. "Génesis y Redefinición de la Matriz Conceptual del Paradigma Utilitarista de Racionalidad.
} 
Sumario: 1. La ordenación del caos. El esfuerzo por comprender la realidad y moverse en ella, antesala de la tolerancia y la intolerancia. 2. Religión y orden. La religión como elemento diferenciador de los pueblos, como criterio para unir a los iguales y separar a los distintos. La integración por el sometimiento. 3. El orden armónico. La integración por la aceptación de la diferencia. 4. La fijación de la identidad y la exclusión del distinto. 5. Religión e identidad en la Roma antigua. 6. El monoteísmo y el libro: la identidad y el pueblo de Israel.

"(...) la persona humana tiene derecho a la libertad religiosa. Esta libertad consiste en que todos los hombres han de estar inmunes de coacción, tanto por parte de individuos como de grupos sociales y de cualquier potestad humana, y esto de tal manera que, en materia religiosa, ni se obligue a nadie a obrar contra su conciencia, ni se le impida que actúe conforme a ella en privado y en público, sólo o asociado con otros, dentro de los límites debidos. Declara, además, que el derecho a la libertad religiosa está realmente fundado en la dignidad misma de la persona humana, tal como se la conoce por la palabra revelada de Dios y por la misma razón natural. Este derecho de la persona humana a la libertad religiosa ha de ser reconocido en el ordenamiento jurídico de la sociedad, de tal manera que llegue a convertirse en un derecho civil."

Es una defensa clara, elocuente y precisa de la libertad religiosa. La define, expone sus principales implicaciones, afirma la autoridad superior de la conciencia individual en esta materia, expresa su vinculación con la dignidad humana, en la que se funda y establece la obligación de su defensa por parte de la sociedad política. Más adelante, el mismo texto dice:

"Ahora bien, la verdad debe buscarse de modo apropiado a la dignidad de la persona humana y a su naturaleza social, es decir, mediante una libre investigación, sirviéndose del magisterio o de la educación, de la comunicación y del diálogo, por medio de los cuales unos exponen a otros la verdad que han encontrado o creen haber encontrado, para ayudarse mutuamente en la búsqueda de la verdad; y una vez conocida ésta, hay que aceptarla firmemente con asentimiento personal."

La libertad religiosa es necesaria para la búsqueda de la verdad; es la única vía para alcanzar la verdad, si es que es alcanzable. Además, en esa busca libre y personal debe poder contarse con la 
comunicación de los resultados de los esfuerzos personales, en el mismo camino, de los demás buscadores. No llegaron a una conclusión distinta los legisladores que redactaron la Primera Enmienda a la Constitución de los Estados Unidos, en 1791, en lo que continúa siendo uno de los hitos modernos en la historia de la civilización de la humanidad.

En la primera de las citas textuales que anteceden, he omitido las palabras iniciales, buscando un pequeño efecto retórico en los lectores que no las hubieran reconocido. Son éstas: "Este Concilio Vaticano declara que (...)".

En efecto, los dos textos citados pertenecen a la Declaración Dignitatis Humanae, sobre la libertad religiosa, aprobada por el Concilio Vaticano II en 1965 y promulgada el mismo año por el papa Pablo VI (Vaticano II, 1965). Estos textos son importantes no ya por lo que dicen, sino por quién lo dice. Expresan la doctrina oficial de la Iglesia romana, estableciendo un profundo cambio en ella. La Iglesia romana ya no tiene la influencia mundial que tuvo, ni siquiera la que tenía en 1965; pero aún así su influencia en las conciencias y las opiniones de una enorme cantidad de gente en todo el mundo sigue siendo muy alta, por lo que vale la pena estudiar la doctrina fijada por el Vaticano II, al margen de las creencias religiosas de cada uno, sobre todo teniendo en cuenta el impacto en la opinión pública que supusieron los cambios doctrinales adoptados por el citado concilio.

El reconocimiento del derecho a la libertad religiosa hecho por la que es la iglesia cristiana con más fieles es especialmente significativo porque corresponde a una institución que, como religiosa, parte de la afirmación y la defensa de la verdad de su credo, afirma que la adhesión a esa verdad por parte de todos aquellos que lleguen a conocerla es imprescindible para la salvación eterna y piensa que tiene el deber de llevar a esa salvación ultraterrena a todos los humanos. Con esas convicciones, la Iglesia romana, como otras muchas iglesias y religiones, ha atacado, a veces a sangre y fuego, esa libertad que ahora proclama. El cambio realizado no es menor.

La negación de la libertad religiosa no ha sido un asunto exclusivamente eclesiástico. Todo tipo de instituciones y las más poderosas de ellas, los Estados y los otros fenómenos políticos más rudimentarios que los precedieron, han hecho lo mismo a lo largo de la historia. La historia humana es la historia del sometimiento de la conciencia más que la de su libertad. Este giro admirable, que se ha producido en los dos últimos siglos (y que, lamentablemente, aún es muy incompleto en su intensidad y 
en su alcance) ha sido la culminación de un esfuerzo de siglos por un objetivo más modesto: la tolerancia religiosa. Las religiones agrupan las convicciones fundamentales de los seres humanos sobre lo que existe y sobre cómo actuar. Es importante reflexionar sobre los caminos que han conducido a la libertad religiosa, a través de la defensa de la tolerancia, porque todo podría haber resultado de otra manera.

Se entiende normalmente que la idea de tolerancia es moderna; todo lo más, se retrotraen sus primeros esbozos a Cicerón o a los primitivos cristianos. Así se hace, por ejemplo, en la Stanford Encyclopedia of Philosophy (Forst, 2017). En el presente trabajo, vamos a intentar rastrearla hasta tiempos mucho más antiguos. Ciertamente, el pleno desarrollo de la tolerancia, tal como la conocemos hoy día, es moderno. Pero eso pasa también con muchas de nuestras concepciones políticas y jurídicas, sin menoscabo de que puedan remontarse sus primeras apariciones a épocas muy anteriores, en las que puedan encontrarse datos que aporten revelaciones relevantes de sentido. En el mundo antiguo hay dos ejemplos notables de tolerancia, ambos ligados a esfuerzos por la construcción de imperios, es decir de unidades políticas que integran a pueblos diversos, con tradiciones políticas y religiosas diferentes, y que pueden permitirnos comprender el sentido primero de la tolerancia; se trata del imperio de Ciro el Grande (siglo VI a. C.) y de la Roma antigua. Junto a ellos, la prevalencia es la de la intolerancia. Su estudio será tan revelador para comprender el significado de la tolerancia como el de esta misma. Si comprendemos cómo y por qué se daba la intolerancia, podremos comprender el sentido y el alcance de la tolerancia.

La idea y la práctica de la tolerancia, además, convocan otros conceptos y usos importantes en la Filosofía política y jurídica, que les son próximos, con los que interactúan y cuyo descubrimiento de sentido es relevante para el de la tolerancia. El Estado, la nación, el pueblo, las personas, la igualdad, la pertenencia, la exclusión, la soberanía...

Todas estas ideas y prácticas interactúan entre sí y con otros fenómenos sociales. Esa interacción no parece que pueda ser descrita como una relación causal; hay demasiadas interrelaciones entre demasiados elementos como para que puedan señalarse conexiones causales; probablemente es que este tipo de conexiones no puedan señalarse con fiabilidad en el mundo moral. En todo caso, dada 
esta complejidad de interacciones, el esfuerzo por comprender el sentido de la tolerancia y sus vicisitudes históricas habrá de repercutir en la comprensión del sentido de todas esas otras ideas e instituciones que interactúan con ella.

\section{La ordenación del caos. El esfuerzo por comprender la realidad y moverse en ella, antesala de} la tolerancia y la intolerancia

"En el principio creó Dios los cielos y la tierra. Y la tierra estaba desordenada y vacía, y las tinieblas estaban sobre la faz del abismo y el Espíritu de Dios se movía sobre la faz de las aguas".

Para comprender la tolerancia y la intolerancia, hay que tener en cuenta que su práctica requiere el paso previo de deslindar lo político-religiosamente igual de lo distinto. Se tolera lo igual, no se tolera lo distinto. Tolerancia e intolerancia, en un cierto sentido, proceden del esfuerzo analítico básico que permite ver y andar por lo que nos rodea. En el principio, entonces, el caos y la oscuridad. No sólo en el cosmos, al que se refiere el libro del Génesis, sino en todo; también en la sociedad. La guerra de todos contra todos, el desorden y las tinieblas: el abismo. El espíritu (el Espíritu de Dios, en el Primer Libro pero, en general, podemos hablar del espíritu a secas), el espíritu comienza la existencia haciendo la luz e imponiendo orden en el caos. Luz, distancia y diferencia. La distancia permite la diferencia. Dios, tras hacer la luz y despejar las tinieblas, distingue las aguas de la tierra seca, y agrupa las aguas en un lugar y la tierra seca en otro. Lo claro permite agrupar y separar lo distinto.

"Antes del mar y de las tierras y, el que lo cubre todo, el cielo, uno solo era de la naturaleza el rostro en todo el orbe, al que dijeron Caos, ruda y desordenada mole y no otra cosa sino peso inerte, y, acumuladas en él, unas discordes simientes de cosas no bien unidas.

Ningún Titán todavía al mundo ofrecía luces, ni nuevos, en creciendo, reiteraba sus cuernos Febe, ni en su circunfuso aire estaba suspendida la tierra, por los pesos equilibrada suyos, ni sus brazos por el largo margen de las tierras había extendido Anfitrite, y por donde había tierra, allí también ponto y aire: 
así, era inestable la tierra, innadable la onda, de luz carente el aire: ninguno su forma mantenía, y estorbaba a los otros cada uno, porque en un cuerpo solo lo frío pugnaba con lo caliente, lo humedecido con lo seco, lo mullido con lo duro, lo sin peso con lo que tenía peso.

Tal lid un dios y una mejor naturaleza dirimió, pues del cielo las tierras, y de las tierras escindió las ondas,

y el fluente cielo segregó del aire espeso. Estas cosas, después de que las separó y eximió de su ciega acumulación, disociadas por lugares, con una concorde paz las ligó." (Ovidio, Metamorfosis, I, 5-25).

En el desenvolvimiento de las agrupaciones humanas, estas dos acciones que hemos visto en el libro del Génesis, y que ahora vemos en la Metamorfosis, la de iluminar donde sólo había tinieblas, para obtener lo claro, y la de ordenar el caos mediante la separación (análisis, discriminación) de lo distinto, y la unión de lo igual y lo próximo; estas dos acciones benéficas de iluminación y de orden también pueden llevar, por exceso a un caos y oscuridad cualitativamente distintos, de modo que devuelven, y no apartan de ellas, a las proximidades del abismo. Los totalitarismos del siglo XX, sin ir más lejos, pueden entenderse, en cierto modo, como el resultado de la pérdida de medida en la luz y en la ordenación. Hay, pues, diversas medidas, con resultados diversos, en el establecimiento del orden. Por eso advertía Ovidio, en el último de los versos citados, que el final del proceso de ordenación del caos fue el establecimiento de "una paz concorde", una paz resultado del ajuste de lo discordante, resultante de la armonía.

Las fases del proceso descrito por Ovidio serían, así, tres. Primero, el caos ("discordes simientes de cosas no bien unidas"). Segundo, la separación, el deslinde de lo distinto y lo semejante. Tercero, la reunión concorde. Tanto Ovidio como el redactor del Génesis se referían a la Creación, entera, al Universo. Pero seguramente reflejan sus convicciones básicas tanto sobre los primeros momentos y la formación de la estructura básica del Universo (la densísima amalgama presumiblemente previa al Big Bang y la violenta dispersión y reunión de materiales posterior, dirían los físicos contemporáneos), cuanto los elementos también básicos del pensar (análisis, síntesis). 
No está de más detenerse en la coincidencia de planteamientos entre el Génesis y la Metamorfosis. Como obras cosmogónicas, reflejan la visión de fundacional de lo existente del mundo antiguo, en dos versiones que reflejan, a su vez, dos de los pilares básicos de nuestra propia visión de lo existente, el judaísmo y el pensamiento griego (la Metamorfosis, en cuanto compendio de la mitología greco-romana, refleja el sustrato común de estas dos civilizaciones). El judaísmo, a su vez, se nutrió en sus orígenes de las religiones mesopotámicas y egipcias, y en general del Creciente Fértil, en cuanto a estos temas (Schama, 2015, I, 1).

\section{Religión y orden. La religión como elemento diferenciador de los pueblos, como criterio para} unir a los iguales y separar a los distintos. La integración por el sometimiento

También la religión es un elemento ordenador de lo caótico. Religión es religación, unión de los iguales, de los que tienen la misma religión, una vez apartados los distintos, los que tienen otra. ${ }^{2}$ Las religiones, por tanto, permiten distinguir, separar a los humanos; y, por otra parte, permite unir a los que son iguales entre sí, a quienes tienen una misma religión. El de la religión es un tipo de unión que incorpora una explicación de su origen, que es al mismo tiempo una explicación de la necesidad de su mantenimiento. Se trata del conocimiento, de la verdad; de una verdad cosmogónica, cosmológica y cosmonómica. Una verdad que revela el origen del cosmos, y su estructura y funcionamiento, entendidos como un devenir reglado, resultado del cumplimiento de unas normas. Los humanos forman parte de ese cosmos, si bien de un modo peculiar, en cuanto pueden incumplir algunas de las normas, aunque deberán arrostrar las consecuencias del incumplimiento en forma de penalidades atroces. Los dioses se parecen a los humanos en su afán vindicativo, dado que los humanos se parecen a los dioses en la libertad. Lo importante ahora es que la religión clarifica (separa lo distinto y une lo que es igual). No por casualidad, la religión se manifiesta desde el principio como vinculada al poder político.

\footnotetext{
${ }^{2}$ Parto de la definición etimológica comúnmente aceptada, que deriva "religión" del latín religare (Real Academia Española, 1737, voz "religión"). El sentido etimológico se refiere a la religación del creyente con su dios. Me permito ampliar ese sentido para incluir la religación común de todos los que creen en un mismo dios. Cicerón, en cambio, derivaba religio de relegere, releer, aludiendo a la actitud del que reconsidera constantemente las exigencias (religiosas) del actuar. (Vid. De Miguel, 1952, voz "religio"). Ese mismo entendimiento de la religión, también partiendo de Cicerón, es el que da Ortega y Gasset (2006, 95), aunque en seguida afirma el colectivismo de la sociedad y la política romanas: "Vivir no era para ellos una faena puramente humana: era convivir con los dioses, que son, ante todo, los dioses de la colectividad." (Ortega y Gasset, 2006, 109).
} 
La unión de poder político y religión debió de ser el método originario para salir del caos, ambos con una referencia inmediata al poder físico, militar, del gobernante, establecido por un dios poderoso. Las primeras fuentes escritas así lo indican, sean los códigos sumerios o la propia estela que contiene el Código de Hammurabi. Tomemos un solo ejemplo: la Estela de Merenptah (ca. 1208, a.C.). Podrían considerarse otros muchos, pero este texto es muy expresivo de esta religación por la fuerza; aparece grabado en una estela correspondiente al faraón del mismo nombre, de la XIX ${ }^{\mathrm{a}}$ dinastía egipcia y que vivió en el siglo XIII a.C.:

Los príncipes están postrados, diciendo: “iClemencia!” Ni uno alza su cabeza entre los Nueve Arcos. ¡La desolación es para los Tehenu; Hatti queda pacificada; se le ha saqueado a Canaán todo lo malo; se ha arramblado con Ascalón; tomada ha sido Gézer; se ha hecho con Yenoam como si no hubiese existido;

Israel ha sido asolado; ya no queda semilla; Hurru se ha convertido en una viuda para Egipto! Todas las tierras unidas están pacificadas; todo el que estaba inquieto ha sido atado por el rey del Alto y el Bajo Egipto (...). ${ }^{3}$

No es necesario entrar en un estudio de las ciudades y naciones mencionadas en la estela, en la que aparece una de las primeras referencias escritas, si no la primera, al pueblo de Israel. Lo que importa ahora es el modo en el que Merenptah logró la paz; mediante el sometimiento, la postración de los príncipes pidiendo clemencia, de modo que "Ni uno alza su cabeza". El resultado, una desolación que recuerda la paz de los cementerios de la que hablaba Immanuel Kant (Kant, 2016). No es todavía la paz de la armonía que buscaba Ovidio.

\section{El orden armónico. La integración por la aceptación de la diferencia}

\footnotetext{
${ }^{3}$ Traducción propia, sobre el texto inglés de M. Lichtheim (Lichtheim, 1976).
} 
De algunos siglos después de Merenptah data otro monumento epigráfico que también marcaba la culminación de una victoriosa campaña militar, pero en el que la paz alcanzada tiene unos rasgos diferentes. Se trata del conocido con el nombre de Cilindro de Ciro. Se conservan dos fragmentos de él en el British Museum, en cuya página web puede encontrarse su descripción detallada, fotografías y una traducción al inglés del texto que contiene ${ }^{4}$. Se trata de un objeto entre cilíndrico y aovado, de unos 22 por 10 centímetros y de arcilla cocida, y con un texto inscrito en babilonio, en escritura cuneiforme. Probablemente se hicieron varias copias del cilindro, que se enterraron en los cimientos de construcciones destacadas emprendidas por orden del rey Ciro el Grande. Su finalidad era conmemorativa y claramente propagandística. ${ }^{5}$ Ciro había conquistado Babilonia en el 539 a. C. como culminación de una campaña guerrera que le había permitido establecer el imperio más grande hasta el momento de los que hubo en el Creciente Fértil. Como culminación de esas conquistas, como habitualmente, a sangre y fuego, Babilonia se rindió sin combatir. Ciro, sin duda, sabía hacer lo mismo que había hecho Merenptah en su campaña "pacificadora", someter por la fuerza a las diversas ciudades y naciones que habrían de componer su imperio; pero fue más allá y se presentó a sí mismo, siendo rey de reyes, como escogido y enviado por el dios de dioses Marduk. Hizo otras cosas:

"Devolví a estas ciudades sagradas de la otra orilla del Tigris, cuyos santuarios habían quedado en ruinas por largo tiempo, las imágenes que solían vivir en ellos y establecí para ellas santuarios permanentes. También reuní a sus antiguos habitantes y les devolví sus moradas. Más aún, restablecí sin daño según las órdenes de Marduk, el gran señor, en sus antiguas

\footnotetext{
${ }^{4}$ https://www.britishmuseum.org/research/collection online/collection object details.aspx?objectId=327188\&partId=1

Consultado el 4 de marzo de 2017.

${ }^{5}$ Hay una historia interesante en relación con el Cilindro de Ciro. Como se menciona en la página web del British Museum, el Cilindro se prestó a Irán con motivo de los grandes fastos que se organizaron en 1971 para la conmemoración de los " 2.500 años de la monarquía persa", con una intención de refuerzo de la legitimación del régimen político existente entonces en Irán, la monarquía de la dinastía Pahlevi. Con esa ocasión empezó a circular un texto falso que se dijo pertenecía al Cilindro de Ciro. Lo que se pretendía con la falsificación era realzar la operación de legitimación, presentando el Cilindro como una defensa temprana de los derechos humanos. Presuntamente, Ciro habría implantado la libertad de circulación, de culto y de empleo y la noción de respeto a los derechos ajenos como límite al ejercicio de los propios. Habría, además prohibido la esclavitud (Escohotado, 2008, p. 116). A pesar de lo burdo de la falsificación, con una extemporaneidad inasumible, tuvo tanto éxito que fue aceptada por el Comité de los Derechos Humanos de las Naciones Unidas (puede verse, por ejemplo, la página web del $60^{\circ}$ aniversario de la Declaración Universal de los Derechos Humanos:

http://www.un.org/en/events/humanrightsday/2008/history.shtml Una narración del episodio y la bibliografía de la discusión académica suscitada puede encontrarse en la entrada correspondiente de la versión inglesa de Wikipedia: https://en.wikipedia.org/wiki/Cyrus Cylinder. Página consultada el 21 de abril de 2017.
} 
capillas, en los lugares que los habían hecho felices, a todos los dioses de Sumeria y Acadia, a quienes Nabónido había traído a Babilonia, provocando la cólera del señor de los dioses."6

En caso de conquista, lo que se acostumbraba en la época era saquear los templos de las ciudades conquistadas y llevarse a la capital las imágenes y los objetos sagrados más preciados. Esto hacía que los habitantes de las ciudades conquistadas, en términos del texto del Cilindro, hubieran quedado "como muertos (vivientes), con (sus rostros) vueltos y su ira (abatida)." Habían perdido los signos de su identidad como miembros de un pueblo y como adeptos de unos dioses determinados y, con la pérdida de esa identidad, habían perdido el sentido de la dignidad propia. Pero Ciro quería inaugurar un nuevo estilo de gobierno. No es un mero conquistador al estilo predatorio primitivo, sino que pretendió (y consiguió) edificar un imperio, una estructura política multinacional y, para ello, se dio cuenta de que necesitaba el respaldo de los pueblos a los que había vencido y, para conseguirlo, se presenta como el protector de todos sus dioses y el restaurador del culto sagrado. Ciro se proponía, como constructor de un imperio, lograr la unidad de gentes que tenía una identidad diversa, que eran miembros de distintos pueblos, con distintos dioses. Se proponía realizar la síntesis armónica. $\mathrm{Su}$ intento tenía un alcance innovador enorme. Aceptaba las diferencias religiosas, es decir las diferencias de identidad nacional porque pensaba que no eran decisivas para el vínculo político, para el vínculo que lo unía a él mismo, como emperador, con los individuos que integran las distintas naciones de su imperio. La religión, la fe en los distintos dioses, había dotado de identidad a las gentes, sacándolas del caos original. Ciro, con el establecimiento de su nuevo estilo imperial, recomponía una unidad basada en la diversidad de identidades. Lo político unía a los que la religión había separado y dotado de identidad, de dignidad. "Llenos de felicidad, lo saludaron como a un amo con cuya ayuda habían vuelto a la vida desde la muerte, habiéndolos salvado del daño y el desastre, y reverenciaron su nombre". El relato debió de haber sido exagerado por motivos propagandistas, pero coincide con el que encontramos, en lo referente al pueblo judío, en el Libro de Esdras, en el que se narra el permiso que dio Ciro a los judíos cautivos en Babilonia para que volvieran a Israel, con los vasos sagrados y los otros objetos de culto que habían sido expoliados por Nabucodonosor, y edificaran un templo a Yahvé. Así se fundó el Segundo Templo de Jerusalén, tras haber quedado asolado el del rey Salomón.

\footnotetext{
${ }^{6}$ Traducción propia del texto inglés contenido en la página mencionada del British Museum.
} 
Hay, en conclusión dos maneras básicas de resolver el orden en las sociedades políticas, de acabar con el caos. La primera, la que hemos visto ejemplificada en Merenptah: un gran cajón, un gran taxón político una unidad mejor cuanto más grande, en la que se incluyen forzadamente unidades más pequeñas que permanecerían al margen si no fueran obligadas por la fuerza de las armas a quedarse incluidas en el taxón, tras incluirlas forzadamente, se anulan sus peculiaridades, sus rasgos diferenciales, ya que esas diferencias se ven incompatibles con la unidad en la que se pretende que permanezcan. En segundo lugar, es posible construir un taxón sumando diversidades. Las diversidades se declaran como accesorias y no se las ve ya como impedimentos para la pertinencia del taxón. De acuerdo con el proyecto imperial de Ciro, era accesorio el dios al que se adorara y el rito con el que se hiciera; lo importante era el sometimiento a su autoridad imperial. Una ordenación del caos sobre la base de la unidad uniformada y otra ordenación a base de elevar la clave de bóveda de forma que el edificio pueda acoger el máximo número de diferencias.

El pueblo hebreo ocupa un lugar destacado en las dos historias analizadas, y es que sus peripecias son especialmente relevantes para la formación de la noción de tolerancia; y lo son con esas dos facetas que se mencionaron anteriormente: Primero, como pueblo, con identidad propia, que pasa a vivir dentro del territorio de otro pueblo, a consecuencia de haber sido derrotado militarmente. Segundo, como pueblo que define su identidad religiosamente, por su oposición a un dios y su sometimiento ("alianza") a otro, en el contexto del señalamiento divino del gobernante.

\section{La fijación de la identidad y la exclusión del distinto}

La ordenación del caos conduce a un segundo enfoque en el problema de la tolerancia. Se trata de la exclusión. Cuando se forma una unidad política o una agrupación humana de cualquier tipo, un taxón como lo hemos denominado, se incluyen en ella -forzadamente o no- individuos o grupos, pero también se excluye a otros. Esta exclusión puede ser total o parcial; en el primer caso el taxón queda restringido y las unidades excluidas pueden pasar a integrar otro taxón distinto; otro Estado, ya sea como reino o como imperio, como Estado unitario o como federación. Si la exclusión es parcial, la unidad excluida queda sometida a la soberanía del taxón pero en un régimen de segregación interior; en un régimen de apartheid o gueto. La tolerancia o la intolerancia tienen estas dos caras contradictorias 
puede forzarse a un grupo a la integración o a la segregación. ${ }^{7}$ En realidad, es más relevante desde muchos puntos de vista la exclusión social que la integración forzosa. Recuérdese no ya lo atroz de la exclusión radical que han supuesto los pogromos, matanzas contra los más variados grupos sociales, o el propio Holocausto del pueblo judío (o Shoah, como se lo debe llamar), sino exclusiones que, sin llegar a la matanza, suponen el apartamiento social, y que se han considerado desde la antigüedad uno de los castigos más terribles que se podían imponer, desde el ostracismo a la excomunión.

En realidad, la inclusión y la exclusión forzosas deben considerarse dos formas distintas de exponer la misma realidad, que es la cancelación de uno de los aspectos de la identidad personal. El ser humano (no está de más recordar la gran afirmación de la Modernidad de que los seres humanos somos individuos, no grupos); el ser humano, pues, construye y expresa en gran parte su identidad por su inclusión en unos grupos y su apartamiento de otros. Somos melómanos y no somos bioquímicos, por ejemplo. La exclusión y la inclusión forzosa, el reconocimiento y la negación, al negar la posibilidad de la identidad personal son un atentado de primer orden contra la dignidad esencial del ser humano. (Fukuyama, 2018, 10).

\section{Religión e identidad en la Roma antigua}

La esclavitud de los hebreos en el antiguo Egipto o en Babilonia, tras la destrucción del Primer Templo de Jerusalén señalan lo que debía ser el caso típico de una población minoritaria, definida religiosamente, y viviendo en un país extranjero. También en la Grecia clásica, los extranjeros que vivían en las diversas polis eran básicamente esclavos. Sólo se permitía la existencia de pequeños grupos de comerciantes que, precisamente por el carácter intrínsecamente adaptativo y no impositivo de la mentalidad mercantil, no planteaban problemas por cuestionar los fundamentos religiosos del poder político. En todo caso, algunos de los dioses locales de estos comerciantes se incorporaron al panteón de las diversas ciudades griegas, sin cuestionar la primacía de los Dioses locales. La situación se volvió mucho más inclusiva de dioses ajenos en las diversas colonias establecidas por los griegos y, sobre todo, con la expansión imperial. Primeramente, con la heterogeneidad cultural y religiosa que supuso el imperio macedonio, sobre todo con Alejandro. Más adelante, con la inclusión de las ciudades griegas en el Imperio romano (Mikalson, 2009).

\footnotetext{
${ }^{7}$ Aunque en el presente trabajo nos centraremos principalmente en la integración y la segregación grupal o colectiva como núcleos de la cuestión de la tolerancia, es importante no perder de vista que existe también una muy significativa perspectiva individual.
} 
La Roma clásica aportó un giro pragmático en este tema como en otros muchos. Roma tuvo constantemente un afán expansionista, con un modelo peculiar. Tras una conquista militar de un pueblo vecino, se producía una asimilación. Pero no se trató nunca de una federación. Roma imperaba. La situación creada tras una conquista era la de una ampliación de Roma; en esta ampliación, según fueran los términos de la rendición, según cómo se hubiera desarrollado la lucha, más o menos caracteres del pueblo vencido se incorporaban a la nueva Roma y, principalmente entre ellos, los dioses. Una veces se aceptaban y se incorporaban al panteón romano, otras se rechazaban y, finalmente, en otras, los dioses nuevos eran declarados dioses municipales, con validez sólo para una localidad determinada (Dumézil, 2000, 425 sigs.).

Así, las nuevas gentes que se iban incorporando a la ciudad-imperio lo hacían, en cierta medida, con sus costumbres y sus dioses. El Panteón se iba ampliando con los dioses y diosas de las ciudades agregadas a medida que lo hacía Roma, y las propias deidades menores de los lugares sagrados (selvas, fuentes, ríos, lagos) extendían, con su protección a los espacios silvestres, los ámbitos del respeto a la naturaleza (Ihering, 1891, p. 174). Esta liberalidad inusitada con lo religioso se instaló sin que sufriera merma la sacralidad de lo político, gracias a la divinización del emperador y la correspondiente introducción del culto que se le debía por esa condición. Se empezó por la divinización de los emperadores a su fallecimiento, para pasar bien tempranamente, ya con Calígula, el tercer emperador, a la divinización del emperador viviente, en pos de los intentos de Augusto de divinizar a Julio César (Churruca, 2007, p. 121), éste mismo aceptando la tradición helenística, que partía de Alejandro, de divinizar al emperador (Churruca, 2007, p. 120).

La estructura de la religión romana en los tres niveles, primero, de culto al emperador (culto público político), segundo, de culto a los dioses y deidades y lugares sagrados (culto inclusivo) y, tercero, de culto a los antepasados y dioses del hogar (lares y penates, culto personal y familiar) establecía una situación de práctica libertad religiosa, sólo limitada por la obligatoriedad del culto al emperador, de carácter cívico-político y que, por otra parte, sólo obligaba a realizar un simple sacrificio vegetal anual. Puede hablarse, de este modo, de la existencia de un régimen asimilable en los hechos a la separación entre religión y política, a través de esta vía paradójica de la absoluta mezcla entre ambos territorios. El resultado permitía un nivel de libertad religiosa que sólo volvería a existir, muchos siglos después, con el liberalismo: 
"La clara discrepancia entre las convicciones personales de los romanos pertenecientes a los niveles sociales cultos y los mitos subyacentes a los ritos del culto oficial llevó a concebir la religio como el fiel cumplimiento de los ritos y ceremonias sin necesidad de adhesión personal interna de quien los practicaba. Se consideraba que el mantenimiento de esas prácticas era útil para el mantenimiento de la tradición, de los valores éticos del pueblo y para fomentar en él la cohesión dentro de la tradición romana" (Churruca, 2007, p. 70).

\section{El monoteísmo y el libro: la identidad y el pueblo de Israel}

La situación habría de quedar rota como consecuencia de la irrupción en el mundo romano de los monoteísmos. Primero, del judaísmo, y después por el cristianismo. El judaísmo estableció una relación muy estrecha entre religión y política, de forma que la sociedad (el pueblo de Israel), su dios (Yahvé, Elohim), y su gobierno de base patriarcal controlado por la unción sacerdotal (jueces y, posteriormente, reyes), se retroalimentan en cuanto a su constitución y legitimidad. Ni el judaísmo, ni el cristianismo admitían el tipo de componendas, los distingos entre adhesión interna y mera adhesión exterior de que nos habla Churruca. Judaísmo y cristianismo son religiones exclusivistas y que piden adhesión completa: "Escucha Israel, el Señor es nuestro Dios, el Señor es Uno" (Deuteronomio, VI, 4). Yahvé y el pueblo de Israel se constituyeron recíprocamente mediante un Pacto, respectivamente, de sometimiento y protección, que habría de ser revitalizado en la Modernidad, cuando los europeos volvieran a buscar su inspiración en el Antiguo Testamento a consecuencia de la insistencia en la lectura directa de los textos básicos que partía del humanismo protestante. Desde el punto de vista del pacto como texto constitutivo de la comunidad, Moisés, Thomas Hobbes, los padres fundadores de los Estados Unidos o Jean Jacques Rousseau están conectados directamente.

La religión judía entera está atravesada por la idea del pacto constituyente. Abrán pacta con Dios y ese pacto lo constituye como Abraham. Isaac, Jacob pactan con Dios (Jacob recibirá, para sí y para su descendencia, el nombre de Israel tras una noche de lucha terrible). Noé concierta un pacto que

podría decirse universal, en cuanto que la humanidad entera procede de él. David pacta la realeza a cambio del Templo que, sin embargo, sólo llegaría a levantar su hijo Salomón. Cuando se funde el cristianismo, se afirmará su procedencia también de un pacto: la Alianza Nueva del perdón, frente a la Alianza antigua de la ley. El Dios del amor frente al Dios de la justicia. 
A los efectos de la presente historia, resulta importante recordar los términos de la alianza de Yahvé con Moisés, tal como se acordó en el monte Horeb, en el desierto del Sinaí. Yahvé comenzó por evocar los méritos que ya tenía acreditados al emancipar a los israelitas de la esclavitud en Egipto (Éxodo, 19, 3). Esta esclavitud hay que entenderla en los términos, habituales en la época, del desplazamiento forzado de una población derrotada. No parece que los israelitas vivieran en el Egipto de los faraones en una situación de especial penalidad. La historia bíblica de José es un indicio, corroborado por otras fuentes, de que los judíos no tenían una mala posición social ni política. El propio Moisés era un personaje con presencia importante en la corte, si no es que era él mismo de origen egipcio, como indican su nombre y la leyenda de su hallazgo por una princesa egipcia en un juncal del Nilo.

Es la relación que entablan los israelitas con Dios la que suscita la conciencia de la esclavitud. La esclavitud en Egipto es una esclavitud religiosa, consistente en el sometimiento a un panteón ajeno, y con dos agravantes: el politeísmo característico de toda la Antigüedad egipcia (menos el breve intervalo de Akenatón) y el carácter divino del faraón, que anticiparía los problemas que después tuvieron los israelitas en el Imperio romano. Es precisamente con Akenatón (XVIII ${ }^{\mathrm{a}}$ dinastía, a mediados del siglo XIV a. C.) con quien se pusieron más claramente de manifiesto dos fenómenos cruciales en ese paralelismo egipcíaco-romano: el papel mediador entre lo divino y lo humano del gobernante, que asume la función sacerdotal en su grado sumo, y la coexistencia de dos niveles religiosos en la misma sociedad y tiempo; una religión oficial, pública (el culto a Atón que impuso Akenatón, realizando una abstracción sobre las diversas divinidades locales solares en Egipto, la deidad protectora local de los griegos, o el culto al emperador en la Roma imperial) y, al mismo tiempo, un culto privado, manifestación de la religiosidad personal. Este culto privado es, a su vez, doble. Por un lado, refleja una práctica de grupo (eclesial), que se concretó en la Antigüedad, frecuentemente, en las religiones mistéricas (el culto a Osiris en Egipto o a Deméter en los misterios eleusinos, en Grecia, los 
misterios órficos o los de Mitra, ya en Roma). ${ }^{8}$ Por otro lado, el culto privado tenía la dimensión personal y familiar del culto a los antepasados, de los lares y penates en Roma. ${ }^{9}$

El enfrentamiento de los israelitas ${ }^{10}$ con la cultura faraónica los define como pueblo en el magma étnico que habían originado las sucesivas conquistas del Imperio egipcio. La salida de la tierra de la esclavitud y la promesa de la tierra propia en Canaán eran el punto de partida de la constitución israelí. Esta constitución, en cuanto basada en un pacto, habría de ser recíproca. Israel se constituiría como el pueblo elegido por Dios y éste, Yahvé, sería el Dios elegido con exclusividad entre todos los dioses del entorno por el pueblo elegido. Ambos se necesitaban recíprocamente para quedar constituido; para ser lo que eran o llegarían a ser. ${ }^{11}$

La significación básica de este enfrentamiento del monoteísmo hebreo con el politeísmo egipcio no queda alterada por la interpretación de Moisés como príncipe egipcio que desea restaurar la religión monoteísta de Atón (Freud, 2015). ${ }^{12}$ Moisés se habría buscado un pueblo propio para sí y para Atón, entre los habiru, el pueblo semita que vivía en una provincia egipcia limítrofe con el Sinaí. Atón y Yahvé serían el mismo Dios, un Dios abstracto, incorpóreo del que el Sol o el fuego telúrico (la columna de fuego o de humo que manifestaría la presencia del Dios mosaico) serían fenómenos. Yahvé es el Dios justiciero, su religión es, por antonomasia, la religión de la Ley, al tiempo que "no puede carecer de importancia que Ikhnatón siempre se calificara a sí mismo, en sus inscripciones, como 'el que vive en Maat' ('Verdad', 'Justicia')" (Freud, 2015, 65). La interpretación de Moisés que proporciona Freud está hoy día bastante desacreditada. Hans Küng, por ejemplo, la equipara, en su falta de fiabilidad, a la visión novelística de Thomas Mann en José y sus hermanos, y dice de ella que se trata

\footnotetext{
${ }^{8}$ Benjamin Constant considera que las religiones mistéricas suponían el intento de restablecer la primitiva religión sacerdotal, frente al politeísmo depurado, principalmente, por Sócrates. Vendría a ser el intento de recuperación de una religión primitiva, irracionalista, sobre la religión cívica. El intento llevaría aparejado el de la introducción de una casta sacerdotal, la de los hierofantes administradores de sacrificios y custodios de los secretos, que se superpondría a la de los gobernantes civiles, en la estructura social (Constant, 2008, 493$513)$.

9 Vid., sobre todo ello, Voegelin, 2000, pp. 34-50.

${ }^{10}$ En lo que sigue, utilizo "pueblo israelita" y "pueblo judío" como sinónimos. Sobre la unión y la desunión de los reinos de Israel (del Norte) y de Judea (al sur, con capital en Jerusalén), véase Mosterín, 2015, p. 39-57. La denominación inicial parece ser la de "hebreos", habiru, que es la que aparece en numerosas fuentes antiguas cananeas y egipcias, incluidas la estela de Merentaph y la Biblia judía, el Tanaj. Habiru sería la palabra para designar, muy significativamente, a grupos de gentes desarraigadas, errantes (MacCulloch, 2010, p. $53)$.

${ }^{11}$ El pacto con Abraham, en cambio fue un pacto unilateral; sólo contenía la promesa que Yahvé le hizo (Eliade, 2005, I, 234).

${ }^{12}$ Sobre la posible influencia de la reforma de Ikhnatón o Akenatón en Moisés, así como el origen egipcio del nombre de Moisés, vid. Eliade, 2005, I, 238.
} 
de "especulaciones psicoanalíticas (concebidas en un principio como una 'novela histórica')" (Küng, 1998, 38). A nuestros efectos, sin embargo, y fuera o no Moisés un príncipe egipcio (el nombre de Moisés sí parece que lo era), el descrédito de Freud como historiador no desvirtúa lo preciso de la vinculación bíblica entre líder carismático, pueblo elegido, Dios legislador y el propio relato religioso. En Filón de Alejandría, el gran intelectual judío que intentó acercar la tradición mosaica al espíritu racionalista de la tradición filosófica clásica, encontramos más cabalmente retratado a Moisés como ese gran líder de su pueblo. En su Vida de Moisés, lo presenta como el titular de las grandes magistraturas del pueblo judío: legislador, sacerdote, profeta y rey (Filón de Alejandría, 2009 b). ${ }^{13}$

Las cláusulas del contrato. En primer lugar, el pueblo. Su compromiso, simple; sólo tiene que obedecer las leyes escritas sobre tablas de piedra por el propio Dios y luego reescritas, cuando Moisés las rompiera, indignado por la desobediencia del pueblo. El Decálogo es la síntesis de esas leyes que se irán desgranando minuciosamente en el propio libro del Génesis y, posteriormente, en el Levítico y el Deuteronomio.

A Dios se le deben además el templo, el culto y los sacrificios. A cambio de la obediencia puntual, sin demora, Dios se obligaba a hacer algo más complejo; después de haber puesto al pueblo elegido en posesión de la tierra prometida debía, usando sus propias palabras, dar "paz a la tierra, y dormiréis sin que nadie perturbe vuestro sueño (...) y la espada no traspasará vuestras fronteras" (Levítico, 26, 6). Establecer la paz.

La ley, el gobierno, el pueblo, el propio Dios dependen del respeto a las clausulas del contrato. Una trabazón tan firme no era compatible con la flexibilidad de la religión romana, en la que, de todos modos, se había introducido un punto de inflexibilidad con el culto al emperador, punto que chocaba irremediablemente con la exclusividad del reconocimiento a Yahvé como dios único y verdadero. Es muy esclarecedor a este respecto, el relato del enfrentamiento entre el emperador Calígula y los judíos

\footnotetext{
${ }^{13}$ En realidad, sólo estas tres últimas son las magistraturas supremas del pueblo judío. La legislación, en la Torá, es obra del propio Yahvé, quien la escribe directamente en las tablas de la Ley, primero, y luego la dicta a Moisés, tras el episodio del Becerro de Oro. Este carácter legislativo primario de Yahvé y secundario de Moisés es enormemente sugerente, por ejemplo en términos de la relación entre autoridad constituyente y autoridad constituida, o de la relación entre el pueblo y el legislador ordinario como representante suyo. Filón, por su parte, como en otras muchas cuestiones, deja abiertas ambas posibilidades: "(...) Moisés, el legislador de los judíos, según algunos, el intérprete de las sagradas leyes según otros (...)." (Filón de Alejandría, 2009 b, 29). En todo caso, hay que entender este asunto en los términos de la explicación del origen divino de las leyes propia del mundo pre-jurídico (anterior a la invención del Derecho por la Roma clásica), según la cual, un Dios legislador da o dicta, según los casos, las leyes al gobernante. El retrato de moisés como legislador es el tema de la primera parte del Libro Segundo de la Vida de Moisés (Filón de Alejandría, 2009 b, 90 ss.).
} 
que relata Filón de Alejandría en su Embajada a Gayo (Filón de Alejandría, 2009 c). El pueblo hebreo, si hacemos caso, a la etimología de habiru, que lo señalaba como pueblo errante, al no tener territorio, buscó en su relación especial con Yahvé el signo de su identidad. Es precisamente esa relación, a través del caudillaje de Moisés, la que le permitió la conquista de su territorio y su propia definición. Yahvé era un Dios exigente que, como dijo él mismo no consentía que se adorara a otros dioses, ni siquiera que él mismo fuera representado, a fin de que ninguna visión suya proporcionada por algún artista se interpusiera entre él y su pueblo. Frente a los dioses de los otros pueblos, Yahvé no es un dios personificado, sino un dios abstracto, conforme con la cualidad intelectual de la religión que versa sobre él; a decir verdad, ni siquiera su nombre debe ser pronunciado, sólo se puede aludirlo: Elohim, Adonai... En el Sancta Sanctorum del Templo de Jerusalén no estaba él, ni siquiera una representación suya, sólo su voluntad expresada en los volúmenes de la Ley, la Torá. Ninguna imagen podía estar presente porque ninguna imagen podía expresar la presencia de El que es.

Gaius Julius Caesar Augustus Germanicus, Calígula, arrastraba una gran aversión a los judíos. Cuando se desató una serie de pogromos contra la numerosa comunidad judía de Alejandría, ésta envió a Roma una embajada presidida por Filón para impetrar la protección imperial. La respuesta, previsiblemente hostil, de Calígula fue la de anunciar algo que iba directamente contra aquellas prescripciones de la exclusividad de Yahvé. Calígula se proponía que se erigiera una estatua suya, representado como Zeus, y que se hiciera además en el Sancta Sanctorum del Templo de Jerusalén, donde la ley mosaica sólo permitía la entrada una vez al año del Sumo Sacerdote. La cuestión, era casus belli para los judíos y hubiera dado lugar a un levantamiento contra Roma que podría conducir incluso a una auto-inmolación masiva. ${ }^{14}$ Los planes de Calígula quedaron súbitamente sin efecto al morir asesinado. Durante la audiencia a la embajada alejandrina, el emperador le había dirigido un duro reproche y advertencia: "Vosotros odiáis a los dioses, pues no creéis que yo sea dios, a quien ya han reconocido todos los demás, sino que para vosotros lo es el Innombrable” (Filón de Alejandría 2009 c, 298).

\footnotetext{
${ }^{14}$ El saqueo del Templo, con la introducción de estatuas de dioses griegos, y la conquista de Jerusalén, con el intento de eliminación de la singularidad judía, ya había dado lugar al gran levantamiento de los Macabeos contra el Imperio helenista seleúcida: "Antíoco hizo publicar en todo su reino un decreto. Todos los pueblos de su Imperio debían abandonar sus costumbres particulares, para formar un único pueblo." (1 Macabeos, 41-42).
} 
Todo este episodio presenta perspectivas interesantes desde el punto de vista de la evolución de la idea de la tolerancia. Primero, claro está, la extrema intolerancia, en los pogromos anti-judíos de Alejandría. La comunidad griega de esta ciudad señera en la Antigüedad desde diversos puntos de vista, invade los barrios judíos, encierra en un gueto a su población y la maltrata, asesina, roba, arrasa sus edificios sagrados. Es el espíritu de la tribu como unidad de aniquilación del distinto, del otro; y (lo que es el principal objetivo) de rapiña, de esquilmación. Por otro lado, el giro argumental que presenta la actuación de Calígula. El gobierno (los reyes, césares, las propias leyes) se presenta en toda la Antigüedad como una institución que los dioses otorgan a ciertos humanos que actúan como mediadores (Carbasse, 2010, cap. I). Calígula, al introducir el culto divino al emperador viviente, lo sitúa entre los dioses, con lo que su poder político se vuelve auto-referente, auto-genético. Podemos entender que esta novedosa auto-genesia de lo político paga, por su existencia, el precio de la restricción de la exigencia a los súbditos de sometimiento; es decir, tenemos aquí un efecto paradójico: el gobernante se apropia de su propia fundamentación religiosa al convertirse en un dios. Al mismo tiempo, sin embargo, reduce su propia importancia al definirse como un dios de una importancia menor ya que se introduce como tal dios en un panteón politeísta en el que, además, sólo se presenta como demandando una adoración exclusivamente cívico-política, dejando que los sentimientos religiosos profundos de la gente se orienten hacia sus propias preferencias personales.

Esta exigencia religiosa menor fue, de todos modos, excesiva para el pueblo judío. La imposición religiosa mínima de Calígula (recuérdese el "consenso entrecruzado" y otros conceptos rawlsianos) era inasumible por el exclusivismo divino judío, así como por su visión de un dios interior: innombrable, irrepresentable y con una morada infranqueable en un Sancta Sanctorum que, por esa razón, no puede compartirse.

Hubo, por consiguiente, puntos de fricción entre la religión judía y Roma, pero encontraron una vía de solución cuando, tras la muerte de Calígula, el emperador Claudio, en su "Carta a los Alejandrinos", acabó con los pogromos y permitió el culto judío si se confinaba al ámbito privado (Sartre, 1994, 435), desapareciendo de las calles y plazas, como se había hecho anteriormente, en el 139 a. C., por el pretor Cornelius Hispallus (Ando, 2003 b, 194). A fin de cuentas, para que se aceptara por las autoridades romanas el culto público de una religión, ésta habría de respetar el sistema religioso 
romano (no suponer un sistema por completo alternativo e incompatible y, al menos en la República, respetar el mos maiorum, la costumbre de los antepasados (North, 2003, 200-201).

El cristianismo también supuso una enmienda a la totalidad del politeísmo romano, aunque sólo fuera por el hecho de rechazar los sacrificios cruentos y reemplazarlos por el gran sacrificio simbólico de la eucaristía.

"El reparto de la carne tras el sacrificio, y el banquete comunal que a veces lo acompañaba, reafirmaba la comunidad humana y sus propias jerarquías internas. (Había muy pocos repartos cívicos en el mundo romano que no reafirmaran el rango social dando más a los ricos que a los pobres - una desasosegante inversión de nuestra propia asunción de que debe darse más a los necesitados.) El sacrificio era lo más parecido a un credo que tenía el mundo romano -un credo en acción. Rechazar el sacrificio, como hicieron los cristianos, era equivalente a rechazar la religión romana tradicional."

(Beard, 2010, 292).

Pero volvamos al judaísmo. Pasada la crisis de Calígula por su asesinato, desaparecen los problemas para los judíos. Roma era un imperio. Un imperio es una unión política de reinos u otras unidades políticas equivalentes; una unidad a base de la pluralidad, E pluribus unum, y debe tolerar la diversidad, como hizo Ciro. Ciertamente la religión judía era un caso límite, con su esquivo Dios, del que solo se conoce su ley, que no tiene apariencia al ser la esencia pura, y que se manifiesta bajo fenómenos extraños -zarzas ardientes, columnas de humo-, y con total intolerancia frente a otros posibles dioses. Pero pudo más la voluntad integradora y el judaísmo llega a ser considerada religio licita, probablemente también porque el ánimo proselitista, que existía en el judaísmo como en cualquier otra religión, era muy moderado entre los judíos, lo que contribuía a que fuera una religión de la que no había que recelar que tuviera un efecto corrosivo en Roma. Además, estaba llena de exigencias rituales y morales enojosas. No era una religión indulgente ni proclive al hedonismo, por lo que no era bien vista entre los romanos, en términos generales (Perez, 2005, 21). El pueblo elegido, aunque no estuviera definido racialmente o lingüísticamente, sino legalmente, no debía ampliarse con facilidad; había que esforzarse para ser admitido. ${ }^{15}$ Si Yahvé era "El que es", lo mismo debería poder

${ }^{15}$ Lo cual no quiere decir que no haya existido entre los israelitas el impulso expansionista, imperialista, como refleja el terrible texto del Deuteronomio 7, 22-25: "Yahvé tu Dios irá arrojando a esas naciones delante de ti, poco a poco (...) te las entregará y les infligirá 
afirmarse de su pueblo especularmente constituido por la Alianza. La tolerancia de Roma y la intolerancia contenida israelita permitieron un periodo de coexistencia.

Un periodo breve. Una religión tan unificada como la judía (un solo dios, un solo texto canónico con una ley fijada y minuciosa, un solo templo) debía reflejar la pluralidad espontánea de los seres humanos y, en el caso de los israelitas ese reflejo se producía a través de las diversas sectas; los saduceos, fariseos y esenios, los principales y minorías muy activas y violentas, los zelotes. La situación se complicó más con los diversos grupos judeocristianos: ebionitas, nazarenos... Una gran masa social pobre y una aristocracia saducea aliada de los romanos; la constante resistencia de los judíos al sometimiento a autoridades forasteras y la mentalidad "macabea", que condujo a una resolución dramática con Vespasiano y Tito, cuando la continua agitación de los judíos llevó a la guerra con Roma, que provocó la destrucción del Segundo Templo en los años 66-70 e. C. (Flavio Josefo, 1999, Libro IV). Poco después, cuando Adriano se enfrentara a un nuevo ciclo violento, se destruye la propia Jerusalén, y se produce la diáspora definitiva.

grandes descalabros hasta que quedan destruidas. Entregará a sus reyes en tu mano y tú borrarás sus nombres de debajo de los cielos: nadie podrá resistir ante ti, hasta que los hayas destruido. Quemaréis las esculturas de sus dioses (...)”. 


\section{OBRAS CITADAS}

ANDO, C. (2003 a), ed.: Roman Religion, Edimburgo, Edinburgh U. P..

ANDO, C. (2003 b): "Introduction to Part V", en Ando, 2003 a.

ARENDT, H. y SCHOLEM, G. (2018): Tradición y política. Correspondencia (1939-1964), trad. L. Maeding y L. Silos, Madrid, Trotta.

BEARD, M. (2010): Pompeii: The Life of a Roman Town, Londres, Profile Books.

CAQUOT, A. (1993): "El judaísmo desde la cautividad de Babilonia hasta la revuelta de Bar Kojva", en Puech, 1993, 136 y sigs.

CARBASSE, J. M. (2010): Histoire du Droit, $2^{\mathrm{a}}$ ed., París, P.U.F.

CHURRUCA, J. de (2007): Introducción histórica al Derecho Romano, Bilbao, Universidad de Deusto.

CONSTANT, B. (2008): De la religión considerada en sus fuentes, formas y desarrollo (1824-1831), ed. T. Todorov y E. Hoffman, trad. A. Neira, Madrid, Trotta.

DE MIGUEL, R. (1952): Nuevo diccionario latino-español etimológico, Madrid, Victoriano Suárez.

ELIADE, M. (2005): Historia de las Creencias y de las Ideas Religiosas (1978), 3 vols., trad. J. Valiente, Barcelona, RBA.

ESCOHOTADO, A. (2008): Los enemigos del comercio, I, Barcelona, Espasa.

FLAVIO JOSEFO (1999): La guerra de los judios (entre el 75 y el 79 d. C.), Libros IV-VII, trad. J. M. Nieto Ibáñez, Madrid, Gredos.

FILÓN DE ALEJANDRÍA (2009 a): Obras Completas, Volumen V, ed. de J. P. Martín, Madrid, Trotta.

FILÓN DE ALEJANDRÍA (2009 b): Vida de Moisés, trad. J. P. Martín, en Obras Completas, Volumen V, págs. 15 y sigs.

FILÓN DE ALEJANDRÍA (2009 c): Embajada a Gayo, trad. J. P. Martín, en Obras Completas, Volumen V, págs. 233 y sigs.

FORST, R. (2017): “Toleration”, The Stanford Encyclopedia of Philosophy, Edward N. Zalta (ed.), en https://plato.stanford.edu/archives/fall2017/entries/toleration/ consultado el 5 de agosto de 2019.

FREUD, S. (2015): Moisés y la religión monoteísta (1937), trad. R. Rey, Madrid, Alianza.

FUKUYAMA, F. (2018): Identity. The Demand for Dignity and the Politics of Resentment, Londres, Profile Books. Hay traducción española por A. García Maldonado (2019), Identidad. La demanda de dignidad y las políticas del resentimiento, Barcelona, Deusto.

IHERING, R. von (1891): El espíritu del Derecho Romano en las diversas fases de su desarrollo, trad. E. Príncipe y Satorres, Barcelona, Librería Editorial de Bailly-Baillière e Hijos.

KANT, I. (2016): La Paz Perpetua, trad. J. Abellán, Madrid, Alianza (Zum ewigen Frieden, Königsberg, 1795).

KÜNG, H. (1998): El Judaísmo. Pasado, presente, futuro, trad. V. A. Martínez de Lapera y G. Canal, Madrid, Trotta, $2^{\mathrm{a}}$. ed.

LACTANCIO (1982): Sobre la muerte de los perseguidores (c. 317-321), trad. R. Teja, Madrid, Gredos.

LE GOFF, J. (2011): ¿Nació Europa en la Edad Media?, M. J. Furió Sancho, Barcelona, Crítica.

LICHTHEIM, M. (1976): Ancient Egyptian Literature, Volume II, Berkeley, U. of California Press, en http://bibledudes.com/biblical-studies/finds/merneptah-translation.php 
consultado el 19 de enero de 2017.

MACCULlOCH, D. (2010): A History of Christianity. The First Three Thousand Years, Londres, Penguin. Hay traducción española, por R. García (2011), Historia de la Cristiandad, Madrid, Debate.

MIKALSON, J. (2009): "Greece”, en Johnston, S. I., ed., Ancient Religions: Beliefs and Rituals across the Mediterranean World, Cambridge, Mass., Harvard University Press.

MOSTERÍN, J. (2015): Los judios. Historia del pensamiento, Madrid, Alianza.

NIXEI, C. (2018): La edad de la penumbra. Cómo el cristianismo destruyó el mundo clásico, trad. R. González Férriz, Madrid, Taurus.

NORTH, J. (2003): "Religious Toleration in Ancient Rome", en Ando, 2003 a, 199-219.

OGILVIE, R. M. (1995): Los romanos y sus dioses, trad. A. Cabezas, Madrid, Alianza.

ORTEGA Y GASSET, J. (2006): Del Imperio romano (1940), en Obras Completas, Tomo VI, Madrid, Editorial Santillana y Fundación Ortega y Gasset.

OVIDIO NASÓN, P. (2002): Metamorfosis, trad. A. Pérez Vega, Alicante, Biblioteca Virtual Miguel de Cervantes, 2002 (Metamorphoseon, 8 d. C.), en http://www.cervantesvirtual.com/nd/ark:/59851/bmccz361 consultado el 8 de agosto de 2018.

PEREZ, J. (2005): Los judios en España, Madrid, Marcial Pons.

PUECH, H.-Ch. -dir.-(1993): Las religiones en el mundo mediterráneo y en el Oriente próximo, I, Formación de las religiones universales y de salvación, en Historia de las religiones, Madrid, Siglo XXI.

REAL ACADEMIA ESPAÑOLA (1737): Diccionario de Autoridades, Tomo V, en

http:/www.rae.es/recursos/diccionarios/diccionarios-anteriores-1726-1996/diccionario-de-autoridades consultado el 14 de marzo de 2017.

SARTRE, M. (1994): El Oriente romano. Provincias y sociedades provinciales del Mediterráneo oriental, de Augusto a los Severos (31 a. de C.-235 d. de C.), trad. M. V. García Quintela y M.-P. Bouyssou, Madrid, Akal.

SCHAMA, S. (2015): La historia de los judios, I, En busca de las palabras: 1000 a.e.c.-1492, trad. J. Rabasseda, Barcelona, Debate.

STEIN, P. G. (2001): El Derecho romano en la historia de Europa. Historia de una cultura jurídica, trad. C. Hornero y A. Romanos, Madrid, Siglo Veintiuno de España Editores.

TEJA, R. (2000): "Introducción. Vida y obras de Lactancio", en Lactancio, 1982, págs. 7 y sigs.

VATICANO II (1965): Declaración Dignitatis Humanae, sobre la Libertad Religiosa, Declaración del Concilio Vaticano II, aprobada por el papa Pablo VI, en http://www.vatican.va/archive/hist_councils/ii_vatican_council/documents/vat-ii_decl 19651207 dignitatishumanae_sp.html consultado el 14 de agosto de 2017.

VOEGELIN, E, (2000): The Political Religions -1938-, trad. V. A. Schildhauer, en Modernity without Restraint, The Collected Works of Eric Voegelin, Vol. 5, ed. M. Henningsen, Columbia y Londres, University of Missouri Press. 
Páginas web citadas

Biblical Studies:

http://bibledudes.com/biblical-studies/finds/merneptah-translation.php

Biblioteca Virtual Miguel de Cervantes. Metamorfosis de Ovidio:

http://www.cervantesvirtual.com/nd/ark:/59851/bmccz361

British Museum. Cilindro de Ciro:

https://www.britishmuseum.org/research/collection_online/collection_object_details.aspx?objectId=327188\&par $\underline{\mathrm{tId}=1}$

Ciudad del Vaticano. Archivos:

http://www.vatican.va/archive/hist_councils/ii_vatican_council/documents/vat-ii_decl_19651207_dignitatishumanae sp.html

Naciones Unidas. Conmemoración del $60^{\circ}$ aniversario de la Declaración Universal de los Derechos Humanos:

http://www.un.org/en/events/humanrightsday/2008/history.shtml

Real Academia Española. Diccionario de Autoridades:

http://www.rae.es/recursos/diccionarios/diccionarios-anteriores-1726-1996/diccionario-de-autoridades

The Stanford Encyclopedia of Philosophy:

https://plato.stanford.edu/archives/fall2017/entries/toleration/

Wikipedia. Cilindro de Ciro:

https://en.wikipedia.org/wiki/Cyrus_Cylinder 